\title{
O BENVENISTE SEMIÓLOGO: DO LABIRINTO DA SEMIOLOGIA À NOÇÃO DE INTERPRETÂNCIA
}

\section{BENVENISTE THE SEMIOLOGIST: FROM THE LABYRINTH OF SEMIOLOGY TO THE NOTION OF INTERPRETANCE}

Heloisa Monteiro Rosário

Universidade Federal do Rio Grande do Sul, UFRGS, Porto Alegre, RS, Brasil

\begin{abstract}
Resumo: Este estudo se interessa pela reflexão semiológica de Benveniste. Considerando-se duas de suas obras, Problemas de linguística geral e Últimas aulas no Collège de France (1968 e 1969), retoma-se a discussão que o linguista faz a respeito da noção de signo e da questão semiológica a partir das ideias de Peirce e de Saussure. Objetiva-se, com isso, mostrar não apenas seu posicionamento teórico em relação a esses dois pensadores, mas também como Benveniste encaminha sua própria discussão no campo da semiologia, o que envolve a noção de interpretância da língua, elaborada e proposta pelo linguista no final dos anos 1960.
\end{abstract}

Palavras-chave: Benveniste; semiologia; interpretância; língua.

Abstract: This study is interested in the reflection on semiology by Benveniste. Considering two of his works, Problems in General Linguistics and Last Lectures: College de France 1968 and 1969, we resume the discussion the linguist held about the notion of sign and about the semiological issue based on ideas by Pierce and Saussure. Therefore, we aim to not only show his theoretical position about these two thinkers but also demonstrate how Benveniste leads his own discussion in the field of semiology, which involves the notion of interpretance of language, developed and proposed by him at the end of the 1960s.

Keywords: Benvenviste; semiology; interpretance; language.

\section{O Benveniste semiólogo e seu fio de Ariadne}

$\mathrm{Na}$ Mitologia Grega, Teseu é o herói de muitas aventuras. Em uma delas, porém, deve seu êxito à astúcia e à coragem de Ariadne, que, apaixonada, lhe dá um novelo de fios antes de ele ser lançado no Labirinto do Minotauro. É graças a esse novelo que, depois de derrotar o terrível mostro, Teseu consegue encontrar a saída e se salvar da morte.

O fio de Ariadne funciona, para o herói, portanto, como um fio 
condutor que o orienta e guia para fora do Labirinto. Ou seja, é o fio que impede que Teseu se perca, interminavelmente, nos meandros e armadilhas do Labirinto, um perigo táo grande quanto aquele que o próprio Minotauro representa ${ }^{1}$.

Dessons (2006) se vale dessa ideia em "Le fil d'Ariane de la sémantique" ["O fio de Ariadne da semântica"] quando, preocupado em situar o pensamento de Benveniste, mostra seu percurso, salientando, através de suas relações com Michel Bréal, Ferdinand de Saussure e Antoine Meillet, assim como com a École Pratique des Hautes Études (EPHE) e o Collège de France, a construçáo de "um paradigma teórico que faz da questão da significaçáo o componente maior da filiação intelectual de Benveniste" (DESSONS, 2006, p. 27, tradução minha). Conforme sugere o autor (Ibidem), como um fio condutor, essas referências todas permitem que Benveniste encontre seu caminho em uma reflexão a respeito da linguagem, centrada na significação, saindo, a seu modo, metaforicamente do Labirinto da semântica. Não se trata, aqui, é claro, da disciplina semântica, mas de um campo de estudos que pensa a significaçáo, o sentido, na linguagem, assim como não se trata, literalmente, da saída desse campo, mas da resolução de um problema: a definição do modo particular como Benveniste pensa a questão da significação em meio a um emaranhado de pontos de vista ${ }^{2}$.

No presente estudo, que recupera uma parte da reflexão desenvolvida em Rosário (2018), influenciada por Dessons, considero um outro Labirinto - o da semiologia - e mais um novelo de fios que, agora, o Benveniste semiólogo desenrola em sua reflexão semiológica.

Nessa perspectiva, apresento a análise que Benveniste faz das ideias de Charles Peirce e de Ferdinand de Saussure a propósito da noção de signo e da questáo semiológica, a fim de mostrar, de um lado, seu posicionamento teórico em relaçáo a esses dois pensadores e, de outro, como o linguista encaminha sua própria discussão. Ou seja, mostro qual desses fios - como o fio de Ariadne - o conduz para fora do Labirinto, permitindo não sua saída literal do campo, mas a resoluçáo de um outro problema: a definição do modo particular como Benveniste pensa a questão semiológica em meio a um emaranhado de pontos de vista. E é, acredito, aquilo que o Benveniste semiólogo propóe em sua problematização da questão que possibilita sua

\footnotetext{
1Para mais detalhes sobre a aventura de Teseu no Labirinto e o papel de Ariadne, conferir, por exemplo, Brandão (1987/2007).

2O que, para Dessons (2006), está ligado à "invenção do discurso", como aponta o título de seu livro, Émile Benveniste, l'invention du discours.
} 
verdadeira saída do Labirinto da semiologia.

Por outro lado, para mim, esses dois pensadores não são, de modo algum, retomados à toa pelo linguista. Se, para o professor, é importante que um amplo balanço do campo seja apresentado a seus alunos, o pesquisador também se vale desse balanço para avançar na discussão (e, no caso de Benveniste, para avançar com suas próprias proposiçôes). Assim, compóem o corpus deste estudo duas de suas obras: tanto os dois volumes de seus Problemas de linguistica gera ${ }^{\beta}$ (com os textos do pesquisador) quanto suas Últimas aulas no Collège de France (1968 e 1969) ${ }^{4}$ (com as aulas do professor). Sua reflexão semiológica atravessa esses dois espaços (o do professor e o do pesquisador) e, neles, vai se constituindo.

Em relação aos textos trabalhados, nas duas primeiras seçóes deste estudo, trato especificamente da primeira parte do artigo "Semiologia da língua", do PLGII, em contraponto com a Primeira aula e as Aulas 2, 3, 4 e 6 do primeiro capítulo das Últimas aulas de Benveniste. Também são referidos os artigos "Tendências recentes em linguística geral", "Vista d'olhos sobre o desenvolvimento da linguística" e "Saussure após meio século", do PLGI. Por sua vez, na última seção, que concerne à apresentação e à discussão da noção de interpretância do linguista, mobilizo a segunda parte de "Semiologia da língua", assim como os textos "Estrutura da língua e estrutura da sociedade" e "Estruturalismo e linguística" do PLGII, além das Aulas 3, 4, 5 e 6 do primeiro capítulo e a Primeira aula do terceiro capítulo de suas Últimas aulas.

\section{No Labirinto da semiologia: com quem Benveniste encontra seu fio?}

Apresento, a seguir, a análise que Benveniste faz das ideias de Peirce e de Saussure a respeito da noção de signo e de uma ciência dos signos, mostrando como o Benveniste semiólogo se posiciona teoricamente em relação a esses dois pensadores, assim como seu modo particular de pensar a questão semiológica.

A primeira parte de "Semiologia da língua" inicia com uma pergunta - "qual é o lugar da língua entre os sistemas de signos?" (BENVENISTE,

3Daqui em diante, também, PLGI e PLGII.

${ }^{4}$ Daqui em diante, também, Últimas aulas.

${ }^{5}$ Ressalto que esse texto não teve sua primeira publicação no PLGII, em 1974, mas na Revista Semiotica, em 1969. 
1969/1989, p. 43). Essa pergunta, para Benveniste (1969/1989, p. 43), traduz "um grande problema" que surge a partir do momento em que Peirce e Saussure, "em completa ignorância um do outro e quase ao mesmo tempo, conceberam a possibilidade de uma ciência dos signos e trabalharam para instaurá-la”.

Benveniste (1969/1989, p. 43), considerando a "confusão que reina neste domínio", procura (ou, ao menos, parece procurar) uma resposta para esse problema através das ideias dos dois pensadores que propuseram, cada um a seu modo, uma ciência dos signos, configurando-se, desse modo, à época, nas referências principais do campo: Peirce no que se estabeleceu como semiótica; Saussure no que se estabeleceu como semiologia. Daí por que são incontornáveis na discussão do linguista, tanto em suas aulas quanto no artigo.

Esse movimento com o qual Benveniste introduz a questão em "Semiologia da língua" é muito próximo do apresentado na Primeira aula do primeiro capítulo das Últimas aulas (datada de 2 de dezembro de 1968). A diferença está no fato de o linguista começar sua explanaçáo, na aula, por uma discussão a respeito da linguística geral, da língua e sua natureza significante ${ }^{6}$ e das noçốes de signo, de sistema e, finalmente, de semiologia. Em seguida, Benveniste (1968/2014, p. 92) afirma que a "teoria geral dos signos foi vislumbrada por John Locke, mas o verdadeiro nascimento dessa teoria ocorreu em dois lugares diferentes": na América, com Peirce, e na Europa, com Saussure.

Nessa mesma aula, por outro lado, Benveniste já aponta o que diferencia essencialmente esses pensadores - o lugar conferido à língua na reflexão de cada um. Segundo o linguista, em Peirce, a "língua como tal está presente em todos os lugares, como uma evidência ou uma necessidade, mas náo como uma atividade específica: ele nunca se interessou pelo funcionamento da língua" (BENVENISTE, 1968/2014, p. 93); em Saussure, pelo contrário, toda a reflexão gira em torno do funcionamento da língua. Sobre Saussure, Benveniste ainda acrescenta:

Ele fundamentou toda a linguística sobre uma teoria do signo linguístico.

\footnotetext{
'Aliás, nesse momento, Benveniste já traz uma importante definição - a língua é "informada de significância, mesmo considerada fora de qualquer emprego, de qualquer utilização particular ou geral. Essa propriedade, se ela nos parece - e ela nos parece de fato - transcender todas as outras, comandará nosso discurso sobre a língua: será um discurso sobre a característica que colocamos em primeiro plano: a língua significa" (BENVENISTE, 1968/2014, p. 90, grifos do autor).
} 
Ele também formulou esta noção fundamental de uma teoria geral dos signos, a semiologia, da qual a linguística seria um dos ramos. Porém, ele não foi mais longe na reflexão sobre a noção geral de signo (BENVENISTE, 1968/2014, p. 93).

No artigo, entretanto, antes de mostrar que a questão da língua os separa radicalmente, Benveniste se debruça primeiro sobre Peirce, referindose a noçóes importantes de seu arcabouço teórico. São mencionadas as noçóes de ícone, índice e símbolo, assim como as de qualisigno, sinsigno e legisigno, todas relativas ao signo; o que, aliás, corresponde à discussão da Aula 2 (datada de 9 de dezembro de 1968), com uma única diferença: ao contrário do que ocorre em "Semiologia da língua", na aula, essas noçôes são um pouco mais explicadas na parte composta pelas notas dos ouvintes.

Nessa discussão, Benveniste demonstra não apenas seu conhecimento de Peirce (que cita em inglês), mas também seu respeito pelo trabalho e pela complexidade do pensamento do filósofo. É importante que se registre isso.

Para o linguista, no entanto, o fio de Ariadne da semiologia não está com Peirce. E isso, acredito, por dois aspectos que caracterizam sua reflexão. De um lado, se os signos são classificados por Peirce, essa classificação produz somente "denominaçóes isoladas, mas não um sistema de conjunto" (BENVENISTE, 1968/2014, p. 98). Ou seja, essa classificação não implica nenhuma articulação entre signos de um mesmo tipo, impossibilitando a ideia de sistema; além do que, ainda, tudo é signo, e um mesmo signo pode ser diferentemente classificado. De outro lado, como referido, a língua não se constitui em um objeto particular da reflexão de Peirce. Essa questão desenvolvida no artigo também aparece na Aula 3 (de 16 de dezembro de 1968), quando Benveniste mostra que, para Peirce, os signos se organizam conforme uma estrutura lógica e não um princípio interno (o próprio sistema) e que, em sua reflexão, tudo é signo.

Seguindo com Peirce, assim, Benveniste (1969/1989, p. 43) não tem como responder à pergunta - "qual é o lugar da língua entre os sistemas de signos?" -, o que envolve uma reflexão tanto sobre a língua em si quanto sobre a ideia de sistema (aspecto não menos importante).

Por isso, de fato, acredito que o linguista não procura (nem em "Semiologia da língua" nem em suas aulas no Collège de France) uma resposta com Peirce. Certamente, nesse campo, Peirce é uma figura que não se pode contornar. Trazê-lo, porém, para a discussão não se deve apenas a isso, uma vez que, de certo modo, trazê-lo também reforça a ideia de que 
o fio que conduz à resposta está, na verdade, com Saussure. É com ele que Benveniste encontra, portanto, seu fio, como fica logo claro na sequência de sua argumentação.

Nesse momento, o autor introduz, pela primeira vez no artigo, a noção de significância, estabelecendo que

\begin{abstract}
Para que a noção de signo não se anule nesta multiplicação ao infinito ${ }^{7}$, é necessário que em alguma parte o universo admita uma DIFERENÇA entre o signo e o significado. É necessário então que todo signo seja tomado e compreendido em um SISTEMA de signos. Esta é a condiçẫo da SIGNIFICÂNCIA. Resulta daí, ao contrário do que pensa Peirce, que todos os signos não podem funcionar identicamente nem pertencer a um sistema único. Dever-se-âo constituir inúmeros sistemas de signos, e entre estes sistemas, explicitar uma relação de diferença e de analogia (BENVENISTE, 1969/1989, p. 45, grifos do autor).
\end{abstract}

Nas palavras de Benveniste (1969/1989, p. 45): “É aqui que se apresenta Saussure", cuja reflexão considera a língua por ela mesma. A partir daí, o linguista se debruça sobre o programa saussuriano formulado no Curso de linguística geral , apresentando não apenas a discussão de Saussure a respeito da definição do objeto da linguística, mas ainda sua proposição de uma nova ciência, a semiologia, discussão que se desenvolve igualmente na Aula 3.

Benveniste aponta que, separando a língua da linguagem e a definindo como um sistema de signos, Saussure coloca a língua como princípio de unidade entre os fatos de linguagem e como princípio de classificação entre os fatos humanos, o que - em um só movimento - funda a linguística como ciência e possibilita o surgimento da semiologia. Eis aqui o fio de Ariadne da semiologia que Benveniste encontra com Saussure; fio que conduz o Benveniste semiólogo em sua reflexão a propósito da língua e de seu lugar entre os sistemas de signos.

Saliento, contudo, que essa "conduçáo" significa tão somente o apontamento de um caminho, pois, na ponta do fio, são as novas questóes colocadas pelo Benveniste semiólogo que o conduzem metaforicamente para fora do Labirinto, permitindo, repito, a resolução de um problema: a definiçấo do modo particular como Benveniste pensa a questáo semiológica em meio a um emaranhado de pontos de vista.

${ }^{7}$ Multiplicação ao infinito que, conforme o linguista, ocorre em Peirce.

${ }^{8}$ Daqui em diante, também, Curso. 


\section{Na ponta do fio: Benveniste propóe novas questôes para a semiologia}

Na primeira parte de "Semiologia da língua" e, também, na Aula 3, Benveniste recupera a discussão em torno da noção de semiologia apresentada no Curso; afinal, é com Saussure, e não com Peirce, que Benveniste segue em sua reflexão semiológica. Essa discussão marca, todavia, apenas a ponta do fio. A saída do Labirinto, por enquanto, ainda não se vislumbra.

Desejando promover a análise semiológica e consolidar as bases da semiologia, Benveniste (1969/1989, p. 50) retoma então "este grande problema no ponto em que Saussure o deixou" e formula novas questôes que a reflexão da segunda parte do artigo pretende responder.

Essas questôes, que também aparecem nas Aulas 4 e 6 (de 6 e 20 de janeiro de 1969, respectivamente), envolvem não apenas os sistemas de signos (seu número, suas diferenças e semelhanças), mas sobretudo as relações existentes entre os sistemas, ou seja, se envolvem sistemas que são ou não autônomos. Com essa problematizaçáo, Benveniste estabelece, de seu ponto de vista, o problema central da semiologia - "o estatuto da língua em meio aos sistemas de signos” (BENVENISTE, 1969/1989, p. 51) -, definindo, consequentemente, seu modo particular de pensar a questáo semiológica.

Nessa perspectiva, para o linguista, é preciso determinar "a noção e o valor do signo" nos conjuntos nos quais se pode estudá-lo; exame esse que "deve começar pelos sistemas não linguísticos" (BENVENISTE, 1969/1989, p. 51).

É importante salientar, aliás, que Benveniste menciona Peirce e sua reflexão sobre o signo no artigo "Tendências recentes em linguística geral" (1954), mas - nesse texto, assim como em "Vista d'olhos sobre o desenvolvimento da linguística" (1963) e "Saussure após meio século" (1963) (todos igualmente republicados, em 1966, no PLGI) -, quando traz, de fato, para a discussão a questão de uma ciência dos signos, o linguista sempre trata das ideias de Saussure e de sua proposiçáo de uma semiologia geral apresentadas no Curso, deixando de lado a perspectiva semiótica. Ou seja, se Peirce e Saussure são referências incontornáveis nessa discussão a propósito de uma teoria ou ciência geral dos signos, o fio que conduz à saída desse Labirinto, desde sempre, Benveniste encontra com Saussure.

Nesses textos, contudo, Benveniste ainda não problematiza a reflexão de Saussure como faz em "Semiologia da língua" e nas aulas do Collège de 
France. Essa problematização somente é apresentada no final dos anos 1960. Daí a importância da indicação, além da primeira publicação de "Semiologia da língua" na Revista Semiotica, das datas das aulas aqui referidas. Tudo se passa, como mencionado, paralelamente e no entrelaçamento desses dois espaços (artigo e aulas) entre os anos de 1968 e 1969, mais especificamente.

\section{Deixando o Labirinto: Benveniste e a noçáo de interpretância}

A noção de interpretância é formulada e apresentada por Benveniste na segunda parte de "Semiologia da língua", que inicia com uma observação do linguista:

O papel do signo é o de representar, o de tomar o lugar de outra coisa evocando-a a título de substituto. Toda definição mais precisa, que distinguiria notadamente muitas variedades de signos, supóe uma reflexão sobre o princípio de uma ciência dos signos, de uma semiologia, e um esforço para elaborá-la (BENVENISTE, 1969/1989, p. 51).

Em seguida, o autor mostra como utilizamos simultaneamente e a cada instante vários sistemas de signos e pergunta: "Nas numerosas e bastante diversas maneiras que têm os signos de se configurar, que princípio introduzir que possa ordenar as relaçóes e delimitar os conjuntos?” (BENVENISTE, 1969/1989, p. 52).

Conforme Benveniste, o traço comum a todos os sistemas e o critério de seu pertencimento à semiologia consiste em sua propriedade de significar (ou significância) e em sua composição em unidades de significância (ou signos). Por outro lado, acrescenta ele, também é preciso descrever como esses sistemas se distinguem entre si, o que envolve os quatro aspectos que caracterizam um sistema semiológico - seu modo operatório, seu domínio de validade, sua natureza e número de signos, assim como seu tipo de funcionamento.

$\mathrm{O}$ linguista indica que os dois primeiros aspectos se relacionam às condições externas, empíricas, do sistema (admitindo variações); ao passo que os dois últimos se relacionam às condiçóes internas, semióticas, do sistema, ou seja, a sua estrutura e a seu funcionamento (não admitindo variaçóes $)^{9}$.

9 A esse respeito, Benveniste (1969/1989) afirma, por exemplo, que o domínio de validade do sistema de sinais de tráfego rodoviário pode ser estendido ou transferido à 
Considerando, então, as condiçóes internas do sistema, Benveniste estabelece que "não se pode 'dizer a mesma coisa' pela fala e pela música", por exemplo, na medida em que são sistemas de base diferente (BENVENISTE, 1969/1989, p. 53). Em outras palavras, a fala e a música envolvem sistemas de natureza e funcionamento distintos, fazendo com que não sejam mutuamente conversíveis. Trata-se do "PRINCÍPIO DE NÃO REDUNDÂNCIA entre sistemas", baseado na ideia de que o "homem não dispóe de vários sistemas distintos para a MESMA relação de significação" (BENVENISTE, 1969/1989, p. 53-54, grifos do autor). O linguista acrescenta, porém, que são mutuamente conversíveis os sistemas que apresentam uma mesma base, como "o alfabeto gráfico e o alfabeto Braile ou Morse ou o dos surdos-mudos” (BENVENISTE, 1969/1989, p. 54).

Benveniste aponta ainda um segundo princípio que decorre do primeiro (o da náo redundância) e o completa. Trata-se da ideia de que não há signo transsistemático, ou seja, da ideia de que não é a identidade substancial de um signo que conta, mas somente sua diferença funcional. Assim, o linguista observa, a título de exemplo, que o branco da bandeira tricolor nada tem em comum com o branco do luto na China, pois o "valor de um signo se define somente no sistema que o integra" (BENVENISTE, 1989, p. 54).

Essas consideraçóes sobre os aspectos que caracterizam um sistema semiológico, de um lado, e sobre os princípios que envolvem as relaçôes entre os sistemas, de outro, são apresentadas por Benveniste, ainda que de modo não tão aprofundado, na parte final da Aula $4^{10}$.

Há, nessa parte, uma observação que merece comentário: referindose à língua ${ }^{11}$ e a seu domínio de validade, Benveniste (1969/2014, p. 106

navegação fluvial e que uma dificuldade externa como a neblina pode impor que sinais sonoros sejam usados no lugar de sinais visuais de tráfego. Essa substituição modificaria tanto o modo operatório desse sistema quanto a natureza de seus signos. Aliás, para o autor, a natureza dos signos de um sistema apenas pode ser modificada temporariamente e em função de questóes externas (a neblina, nesse caso).

${ }^{10}$ Trata-se da parte que se encontra nas páginas 106 e 108 da edição brasileira das Últimas aulas, que é, aliás, quase que inteiramente composta por notas dos ouvintes de Benveniste (nesse caso, pelas notas de Jean-Claude Coquet e Jacqueline Authier-Revuz).

${ }^{11}$ Para mim, nesse momento, o linguista se refere à língua-idioma e não à língua como sistema de expressão; expressóes que utiliza na Aula 6: "Será preciso estabelecer uma distinção entre a língua, enquanto sistema de expressão - sem a qual não há sociedade humana possível -, e a língua-idioma, que é particular. É a língua como sistema de expressão que é o interpretante de todas as instituiçôes e de toda a cultura" (BENVENISTE, 1969/2014, p. 117). Essa distinção, 
[nota de ouvinte]) afirma que esse "sistema semiológico não é, e não pode ser, universal”, reforçando, com isso, a estreita relaçâo entre cada sistema semiológico e o meio cultural específico no qual cada sistema se inscreve e, portanto, significa. Essa relação é igualmente sustentada em um texto de 1968, "Estruturalismo e linguística", quando Benveniste (1968/1989, p. 22) define a cultura como um sistema de valores que se imprimem na língua, e em "Semiologia da língua", quando postula que um mesmo meio cultural produz e alimenta todos os sistemas que lhe são próprios (BENVENISTE, 1969/1989, p. 54).

É importante salientar que as consideraçóes do final da Aula 4 surgem após a discussão que Benveniste faz das ideias de Saussure, nessa mesma aula e também na Aula 3, a respeito da configuração da língua (sua natureza significante: a língua é feita de signos) e de sua relação com a semiologia (os signos da língua formam um sistema, um sistema semiológico).

O Curso traz, desse modo, as bases para a reflexão semiológica de Benveniste, e isso possibilita que o linguista afaste uma visão de signo como representaçáo do mundo, uma visão filosófica, na medida em que o signo não representa, mas significa. E significa, então, não por uma identidade substancial sua, mas na relaçáo que estabelece com os outros signos do sistema do qual faz parte; sistema esse pertencente a um determinado meio cultural, ou seja, instituído pelo homem em sua relação com outro homem, o que mostra, por outro lado, a estreita relaçáo entre o antropológico, estruturante de sua teoria da linguagem, e a reflexão semiológica de Benveniste.

No Labirinto da semiologia, o fio está, de fato, com Saussure. Em sua ponta, no entanto, o Benveniste semiólogo - interessado em uma "definição mais precisa [de signo]" (BENVENISTE, 1969/1989, p. 51) e no desenvolvimento de uma reflexão semiológica - formula novas questôes, especialmente sobre as relaçóes entre os diferentes sistemas. Por isso, sua preocupaçáo (tanto nas aulas no Collège de France quanto em "Semiologia da língua") em determinar não apenas o que há de comum entre esses sistemas, mas ainda (e sobretudo) o que os distingue.

Seguindo essa perspectiva, o linguista estabelece duas condiçóes a

aliás, já aparece no artigo "Estrutura da língua e estrutura da sociedade" (1968/1970), no qual Benveniste (1970/1989, p. 96) defende que os termos "língua" e "sociedade" admitem duas diferentes acepçôes, dois diferentes níveis de análise - um histórico (a sociedade chinesa, francesa etc./a língua chinesa, francesa etc.) e outro fundamental (a sociedade como coletividade humana, base e condiçáo primeira da existência dos homens/a língua como sistema de formas significantes, condiçấo primeira da comunicação). E é esse nível fundamental que interessa ao linguista. 
propósito das relaçôes entre os sistemas semióticos. A primeira condição é que a relação entre os sistemas semióticos seja, ela mesma, de natureza semiótica (ou seja, envolvendo um sistema de signos, um sistema significante). Benveniste acrescenta, ainda, que essa relação será determinada pela açáo de um mesmo meio cultural, "que de uma maneira ou de outra produz e alimenta todos os sistemas que lhe são próprios" (BENVENISTE, 1969/1989, p. 54). A segunda, por sua vez, define que a relação semiótica entre os sistemas será uma relação entre sistema interpretante e sistema interpretado, na medida em que se trata de "determinar se um sistema semiótico dado pode se autointerpretar ou se ele deve receber sua interpretação de um outro sistema" (BENVENISTE, 1969/1989, p. 54, grifo meu).

Essa é, cabe observar, a única ocorrência do termo "interpretação" no artigo "Semiologia da língua". Saliento que, nesse contexto, não se deve compreendê-lo em uma perspectiva hermenêutica - ou seja, a da atribuição de um determinado sentido ou mesmo do sentido-, mas em uma perspectiva semiológica. Desse modo, "interpretaçáo" se refere à relação apresentada mais adiante no texto (" $3{ }^{\circ}$. A terceira relação entre sistemas semióticos será denominada RELAÇÃO DE INTERPRETÂNCIA” (BENVENISTE, 1969/1989, p. 62, grifo do autor)), segundo a qual, para Benveniste, a língua (sistema interpretante), através de sua modelagem semiótica (sua estrutura e seu funcionamento particulares), significa os outros sistemas (sistemas interpretados). Ou seja, a língua se configura no sistema interpretante porque apresenta uma dupla significância, a significância do modo semiótico e a do modo semântico; por sua vez, os sistemas interpretados apresentam uma significância unidimensional, a significância do modo semiótico ou a do modo semântico. Com isso, o que está em questão aqui é, antes de tudo, como um sistema significa e não $o$ que esse sistema significa.

Observo que Benveniste utiliza a expressão "relação de interpretância" em "Semiologia da língua" e também em sua última aula no Collège de France (a Primeira aula do terceiro capítulo (de $1^{\circ}$. de dezembro de 1969)): “3) Relação de 'interpretância' (é preciso forjar conceitos para avançar): ela se estabelece entre sistema interpretante e sistema interpretado" (BENVENISTE, 1969/2014, p. 190 [nota de ouvinte]). Por outro lado, em uma aula anterior, na Aula 5 (de 13 de janeiro de 1969), o linguista utiliza a expressão "relação de interpretaçáo":

É preciso agora introduzir, na análise descritiva e comparativa dos sistemas semiológicos, uma nova relação, que Saussure não mencionou, nem talvez tenha visto: a relação de interpretação. Trata-se de determinar se o sistema 
semiológico considerado pode se interpretar por si mesmo ou se ele deve receber sua interpretaçáo de outro sistema semiológico. A questão que eu coloco é a da relação de interpretaçấo entre sistemas (totalmente diferente da noção de interpretante em Peirce) (BENVENISTE, 1969/2014, p. 109, grifos do autor).

Há, ao que parece, portanto, uma certa flutuação entre os termos "interpretação" e "interpretância", mas Benveniste acaba optando pelo segundo. Vale ressaltar, de todo o modo, dois aspectos: 1) a proximidade das formulaçóes do linguista a esse respeito tanto no artigo quanto na Aula 5; 2) o alerta de Benveniste para o fato de que sua formulaçáo em nada corresponde à noção de interpretante formulada por Peirce.

A relação de interpretância envolve, por conseguinte, para o linguista, a língua (o sistema interpretante) em sua relação com os outros sistemas (os sistemas interpretados), compreendendo diferentes questóes discutidas em textos do PLGII (sobretudo no artigo "Semiologia da língua") e/ou em suas Últimas aulas.

Essa relação, por fim, está ligada a uma propriedade constitutiva da língua (sua propriedade de interpretar), na qual se fundamenta o princípio norteador, o axioma, de sua reflexão semiológica, uma vez que é a língua - e somente a língua (devido a sua dupla significância) - que "pode, em princípio, tudo categorizar e interpretar, inclusive a si mesma" (BENVENISTE, 1969/1989, p. 62).

\section{Palavras finais}

Benveniste, assim como Teseu, não se perde nos meandros do Labirinto e, graças ao fio de Ariadne, também encontra uma saída. No Labirinto da semiologia, o linguista se depara com os pontos de vista de dois grandes pensadores que já haviam, cada um a seu modo, se debruçado sobre a noção de signo e a questão semiológica - Peirce e Saussure - e, nesse emaranhado de fios, não apenas escolhe qual deles seguir, mas também formula suas próprias questóes para o campo, problematizando-o.

Nessa perspectiva, considerando diferentes artigos de seus Problemas de linguística geral, sobretudo o artigo "Semiologia da língua”, e suas Últimas aulas no Collège de France (1968 e 1969), apresento a discussão de Benveniste a respeito das ideias de Peirce e de Saussure no campo da semiologia com o propósito de mostrar tanto seu posicionamento teórico em relação a 
ambos quanto o modo particular como o linguista encaminha sua reflexão semiológica, ou seja, sua saída efetiva do Labirinto da semiologia. Isso se dá paralelamente e no entrelaçamento de dois diferentes espaços: o do professor, nas aulas, e o do pesquisador, nos artigos.

Como mostrado, se é com Saussure (em cuja reflexão a língua está no centro) que Benveniste encontra o fio que o guia, deixando, então, Peirce de lado, na ponta desse fio náo está o fim do perigo, pois ainda é preciso determinar o que tem a língua de especial em relação aos outros sistemas semiológicos, assim como que relaçôes existem entre esses sistemas. Não basta, desse modo, seguir com Saussure, é preciso trazer novas questóes e, consequentemente, novas respostas para o campo, que se relacionam, afinal, com o modo como a língua e os demais sistemas semiológicos significam, assim como com a relação de significância que aí se estabelece: a língua, como interpretante, significando os sistemas interpretados.

Benveniste mostra, com isso, que a noção de interpretância engloba, de um lado, uma relação específica entre sistemas semiológicos (a relação de interpretância) e, de outro, uma propriedade específica da língua (sua propriedade de interpretar, sua interpretância). Isso não apenas porque a relação de interpretância depende dessa propriedade específica da língua, mas também porque a propriedade de interpretância da língua se mostra através dessa relação semiológica, uma relação envolvendo a língua como sistema interpretante e os sistemas interpretados (a relação de interpretância, portanto). Desse modo, essas duas ideias de interpretância - como relação entre sistemas e como propriedade intrínseca da língua -, para mim, estão absolutamente imbricadas e são elas que possibilitam que o Benveniste semiólogo complete seu caminho para fora do Labirinto.

Nesse Labirinto da semiologia, portanto, se uma das pontas do fio de Ariadne está com Saussure, aquela que aponta a saída está, sem dúvida, com o próprio Benveniste e traz, em seu centro, a noção de interpretância.

\section{Referências}

BENVENISTE, Émile. Problèmes de linguistique générale, 1. Paris: Éditions Gallimard, 1966. 1974.

. Problèmes de linguistique générale, 2. Paris: Éditions Gallimard, 
Problemas de linguística geral II. Campinas: Pontes, [1974] 1989.

. Problemas de linguística geral I. Campinas: Pontes/Editora da Unicamp, [1966] 1995.

. Dernières leçons: Collège de France (1968 et 1969) (Orgs. JeanClaude Coquet e Irène Fenoglio). Paris: EHESS/Gallimard/Seuil, 2012.

. Últimas aulas no Collège de France (1968 e 1969) (Orgs. JeanClaude Coquet e Irène Fenoglio). São Paulo: Editora Unesp, [2012] 2014. BRANDÃO, Junito de Souza. Mitologia grega. Vol. III. Petrópolis: Vozes, [1987] 2007.

DESSONS, Gérard. Émile Benveniste, l'invention du discours. Paris: Éditions IN PRESS, 2006.

ROSÁRIO, Heloisa Monteiro. Um périplo benvenistiano: o semiólogo e a semiologia da língua. 2018. 174 p. Tese (Doutorado em Linguística) - Instituto de Letras, Universidade Federal do Rio Grande do Sul, Porto Alegre, 2018.

SAUSSURE, Ferdinand de. Cours de linguistique générale. Edição crítica preparada por Tullio de Mauro. Paris: Éditions Payot (Payothèque), [1916] 1976.

2006.

. Curso de linguística geral. São Paulo: Editora Cultrix, [1916] 